\title{
THE
}

\section{Urban proximity while breeding is not a predictor of perfluoroalkyl substance contamination in the eggs of brown pelicans}

Bradley P. Wilkinson

Anna R. Robuck

University of Rhode Island

Rainer Lohmann

University of Rhode Island, rlohmann@uri.edu

Heidi M. Pickard

Patrick G.R. Jodice

Follow this and additional works at: https://digitalcommons.uri.edu/gsofacpubs

The University of Rhode Island Faculty have made this article openly available.

Please let us know how Open Access to this research benefits you.

This is a pre-publication author manuscript of the final, published article.

Terms of Use

This article is made available under the terms and conditions applicable towards Open Access

Policy Articles, as set forth in our Terms of Use.

\section{Citation/Publisher Attribution}

Wilkinson, B. P., Robuck, A. R., Lohmann, R., Pickard, H. M., \& Jodice, P. G. R. (2021). Urban proximity while breeding is not a predictor of perfluoroalkyl substance contamination in the eggs of brown pelicans.

Science of The Total Environment, 803, 150110. https://doi.org/10.1016/j.scitotenv.2021.150110

Available at: https://doi.org/10.1016/j.scitotenv.2021.150110

This Article is brought to you for free and open access by the Graduate School of Oceanography at DigitalCommons@URI. It has been accepted for inclusion in Graduate School of Oceanography Faculty Publications by an authorized administrator of DigitalCommons@URI. For more information, please contact digitalcommons-group@uri.edu. 


\section{ABSTRACT}

2 Identifying sources of exposure to chemical stressors is difficult when both target organisms and

3 stressors are highly mobile. While previous studies have demonstrated that populations of some

4 organisms proximal to urban centers may display increased burdens of human-created chemicals

5 compared to more distal populations, this relationship may not be universal when applied to organisms

6 and stressors capable of transboundary movements. We examined eggs of brown pelicans (Pelecanus

7 occidentalis), a nearshore seabird with daily movements ranging from local to $50 \mathrm{~km}$ and annual

8 migrations ranging from year-round residency to $1,500 \mathrm{~km}$. Thirty-six eggs from three breeding colonies

9 located at increasing distances to a major urban center (Charleston, South Carolina, USA) were analyzed

10 for concentrations of per- and polyfluoroalkyl substances (PFAS). Areas of high use for each colony

11 during the breeding season were also assessed via the tracking of adult pelicans from each colony using

12 GPS-PTT satellite transmitters and overlapped with measures of relative urbanization via land cover

13 data. We report potentially significant PPFAS concentrations in the eggs of pelicans $(175.4 \pm 120.1 \mathrm{ng} / \mathrm{g}$

14 w wt. SD), driven largely by linear perfluorooctane sulfonate (n-PFOS) (48 - 546 ng/g w wt.). Residues of

15 the precursor compound perfluorooctane sulfonamide (FOSA) were also present in pelican eggs,

16 suggesting continued exposure of local wildlife beyond implemented phaseouts of some PFAS. For most

17 analytes, egg concentrations did not exhibit a significant spatial structure despite some differentiation in

18 high-use areas unlike similar data for another regional apex predator, the bottlenose dolphin (Tursiops

19 truncatus). We suggest that the partially migratory nature of brown pelicans during the non-breeding

20 season, combined with daily ranges that may extend to $50 \mathrm{~km}$ from local point sources, may have

21 homogenized exposure across individuals. Charleston likely remains a major source for PFAS in the

22 overall region, however, given the high concentrations observed as well as known releases of PFAS in

23 the nearshore environment. 


\section{KEYWORDS}

25 Brown pelican; perfluoroalkyl substances; urban; tracking; GPS; seabird

\section{$26 \quad 1.1$ INTRODUCTION}

Ranging behaviors of highly mobile organisms can expose these species to lethal and sublethal

28 stressors not experienced by more sedentary organisms (Jodice \& Suryan 2010, Mello et al. 2016, Odsjö

29 1975). The risks to vagile organisms are amplified when the stressors themselves are also mobile in

30 nature, capable of affecting organisms across relatively broad spatial or temporal scales (Cabrera-Cruz et

31 al. 2018, Henkel et al. 2012). The opportunity for individuals far from local sources of exposure to

32 encounter the stressor should be greater when both organism and stressor are capable of frequently

33 moving among systems, compared to organisms which occupy a distinct spatiotemporal distribution

34 removed from the stressor or for which the stressor is relatively concentrated in a given area. Proximity

35 to sources of environmental stressors may therefore only be a good predictor of exposure for relatively

36 sedentary populations or those with distinct, consistent, or local ranges, and may not be as relevant for

37 highly mobile species interacting with a highly mobile environmental stressor (Adams et al. 2008, Power

38 et al. 2020).

39 Anthropogenic chemicals, including compounds of emergent interest such as per- and

40 polyfluoroalkyl substances (PFAS), can act as mobile stressors because they are capable of long-range

41 dispersal from point sources (Lohmann et al. 2007). PFAS are widespread chemicals that are persistent

42 in both marine and terrestrial environments worldwide (Houde et al. 2006a). Manufactured for their

43 stability and ability to repel both oily and aqueous substances, PFAS have been used for coating paper

44 and packaging products, non-stick cookware, stain-resistant carpet and clothing, as industrial

45 surfactants, and in fire-fighting foams (Sunderland et al. 2019). In production since the 1940s, PFAS

46 contamination in the environment has occurred globally via both direct release and remote transport 
47 (Armitage et al. 2009). Perfluorooctane sulfonate (PFOS) and perfluorooctanoate (PFOA), two of the

48 most commonly-detected PFAS, have been observed to be pervasive in the blood of both wildlife and

49 human populations, and are associated with harmful and diverse biological effects across taxa (Fenton

50 et al. 2020, Houde et al. 2006a, Houde et al. 2011, Sunderland et al. 2019).

51 Exposure to PFAS can vary by physicochemical properties of the compound, toxicokinetic and

52 ecological qualities of the organism at risk, or characteristics of the ecosystem within which the

53 organism resides. For example, PFAS bioaccumulate and biomagnify in apex predators via direct

54 consumption of contaminated prey, making them particularly harmful to species that occupy upper

55 trophic levels (Houde et al. 2006b). Individual exposure can also be affected by intrinsic properties of the

56 ecosystem in which the species forages as well as the behavior of the organism itself. For example,

57 large-scale boundary habitats (i.e. coastal systems) which integrate pollution inputs from both marine

58 and terrestrial domains may present a higher risk to individuals that forage there as opposed to

59 individuals that forage in systems that tend to function as isolated units or have less input from adjacent

60 systems (i.e. pelagic habitats or upland systems) (Crain et al. 2009). Furthermore, exposure potential

61 may not be spatially predictable within an ecosystem, and different aspects of the abiotic environment

62 may serve to collect or distribute risk. For example, although areas with high levels of urban

63 development can concentrate anthropogenic stressors such as toxic pollutants (Adams et al. 2014,

64 Gewurtz et al. 2016), the transport capabilities of many ecological toxicants can result in high levels of

65 exposure even to organisms relatively far from source inputs (Robuck et al. 2020). The long-range

66 broadcasting of risk may thus create a heterogenous exposure landscape that is not defined simply by

67 the location of the source.

68 Our goal was to assess PFAS concentrations in the eggs of a highly mobile apex predator

69 breeding near an urbanized landscape. Charleston, South Carolina, USA is a rapidly developing city

70 located within a complex coastal morphology of rivers, estuaries, and nearshore marine environments. 
71 Prior research suggests that habitats in the Charleston region have significantly elevated levels of PFAS

72 relative to other regions (Keller et al. 2005, Houde et al. 2006b, Vander Pol et al. 2012, Bangma et al.

73 2017). For example, White et al. (2015) reported sediment PFAS concentrations from estuarine habitats

74 in and around Charleston Harbor in excess of any other previously examined U.S. city, with

75 approximately half of tested sites within the study area above the global median concentration for PFOS

76 (0.54 ng/g d wt.). Bottlenose dolphins (Tursiops truncatus) resident within the harbor possess plasma

77 PFAS levels comparable to occupationally exposed humans and are some of the highest recorded in

78 marine mammals globally (Houde et al. 2005, Houde et al. 2006b, Fair et al. 2013, Fair \& Houde 2018).

79 Several fish species frequently consumed by both humans and wildlife in the Charleston area also were

80 commonly above recommended levels for safe consumption by mammals, posing a potentially

81 significant health risk (Fair et al. 2019).

82 Here we assess concentrations of 24 PFAS in 36 eggs of a locally abundant seabird, the Eastern

83 brown pelican (Pelecanus occidentalis carolinensis). Pelicans nest colonially on only 2-3 islands within

84 the vicinity of Charleston in any given year, and these islands and the colonies on them vary in both

85 distance from the urban center $(\sim 2-35 \mathrm{~km})$ as well as in the number of breeding adults ( $\sim 250-3000$

86 pairs). We hypothesized there would be an inverse relationship between distance to Charleston Harbor

87 and SPFAS, with birds breeding closer to the urban center and therefore also closer to likely point

88 sources acquiring greater toxicity burdens. Therefore, we sought to (i) assess the presence of PFAS in

89 pelican eggs from the Charleston Harbor region relative to published values for other seabird eggs

90 collected from other locales and (ii) investigate the influence of urban habitat use on concentrations of

91 PFAS in pelican eggs using movement data from an additional subset of GPS-tracked adult pelicans from

92 each colony.

93

94 METHODS 


\subsection{Sample collection and processing}

96 Eggs for contaminant analysis were collected from three breeding colonies of Eastern brown pelicans 97 located at progressively greater distances from urban Charleston (Figures $1 \& 2)$. Castle Pinckney $\left(32^{\circ}\right.$

$9846^{\prime} 26^{\prime \prime} \mathrm{N}, 79^{\circ} 54^{\prime} 40^{\prime \prime} \mathrm{W}$ ) is an urban seabird colony centrally located on a small shell island within the

99 harbor and has hosted approximately 250 breeding pairs of brown pelicans near-annually since

100 individuals first started nesting in 1999 (Jodice et al. 2007). Bird Key Stono ( $32^{\circ} 38^{\prime} 00^{\prime \prime} \mathrm{N}, 79^{\circ} 58^{\prime} 04^{\prime \prime}$ W)

101 is a larger sand island located at the mouth of the Stono River approximately $17 \mathrm{~km}$ to the southwest of

102 Charleston Harbor. This island is a regionally important nesting site for brown pelicans, with

103 approximately 3,000 nesting pairs annually since recolonization in 2014 (Jodice et al. 2007, F. Sanders

104 2021). Deveaux Bank ( $32^{\circ} 32^{\prime} 46^{\prime \prime} \mathrm{N}, 80^{\circ} 11^{\prime} 30^{\prime \prime} \mathrm{W}$ ) has hosted annual breeding pairs of brown pelicans

105 since 1989, with an average count of 1,300 nests per year (Jodice et al. 2007). Deveaux Bank is located

106 approximately $37 \mathrm{~km}$ southwest of Charleston Harbor at the outflow of the North Edisto River.

107 Thirty-six eggs were collected in total, with efforts split evenly among colonies $(n=12$ per

108 breeding site). All eggs were collected between 10 May 2019 and 15 May 2019, with procedures

109 approximating those of Vander Pol et al. (2012). Briefly, eggs were floated to estimate approximate age, 110 with an effort made to collect eggs in as early a stage of incubation as possible. Brown pelicans typically

111 lay a clutch of three eggs, and we aimed to collect first-laid eggs as these tend to have higher

112 concentrations of maternally transferred chemical compounds than second- and third-laid eggs (Vicente

113 et al. 2015, Parolini et al. 2021). The laying order of eggs was based on visual inspection of shell

114 cleanness. Only eggs which sank in water were collected for analysis, with resting angles ranging from

115 approximately $0^{\circ}-60^{\circ}$ relative to the bottom of the floating vessel (Rush et al. 2007). Only one egg was

116 collected per nest, and an attempt was made to distribute the collection throughout the spatial

117 footprint of the colony $\left(\sim 0.01 \mathrm{~km}^{2}\right)$. 
Eggs were transported from the colony to an off-site refrigerator $\left(4^{\circ} \mathrm{C}\right)$ until homogenization.

119 Egg contents were separated from the shell and homogenized using a bag mixer (BagMixer $400 \mathrm{~W}$,

120 Interscience Laboratories, Inc.) in non-filter $400 \mathrm{~mL}$ polyolefin blender bags (BagLight PolySilk,

121 Interscience Laboratories, Inc.). Aliquots of homogenized sample (15 mL) were then transferred to

122 polypropylene vials via individual transfer pipettes and stored at $-80^{\circ} \mathrm{C}$ until sample extraction and

123 analysis (March 2020).

\section{$124 \quad 2.2$ Sample preparation and analysis}

Sample preparation and analysis followed a modified protocol based on Chu \& Letcher (2008).

126 Sample aliquots were thawed at room temperature, and $0.5 \mathrm{~g}$ of homogenate were weighed into

127 polypropylene centrifuge tubes and spiked with $20 \mu \mathrm{L}$ of isotopically labeled internal standard $(0.5$

$128 \mathrm{ng} / \mu \mathrm{L})$. Samples were extracted with $4 \mathrm{~mL} 10 \mathrm{mM}$ potassium hydroxide $(\mathrm{KOH})$ in methanol $(\mathrm{MeOH})$ and

129 vortexed. Following sonication (20 $\mathrm{min}$ ) and centrifugation ( $2 \mathrm{~min} \times 4000 \mathrm{rpm}$ ), the resulting supernatant

130 was transferred to $15 \mathrm{~mL}$ polypropylene tubes. Remaining pellets received a secondary wash of $4 \mathrm{~mL} 10$

$131 \mathrm{mM} \mathrm{KOH}$ in $\mathrm{MeOH}$, sonication, and centrifugation (10 $\mathrm{min} \times 4000 \mathrm{rpm}$ ), with supernatant decanted and

132 added to the prior fraction.

133 Supernatant samples were diluted with $80 \mathrm{~mL}$ of Milli-Q (MQ) water prior to solid phase

134 extraction (SPE). Waters Oasis WAX cartridges (Waters Corp.) were preconditioned with $4 \mathrm{~mL} 0.1 \%$

135 ammonium hydroxide $\left(\mathrm{NH}_{4} \mathrm{OH}\right)$ in $\mathrm{MeOH}, 4 \mathrm{~mL} \mathrm{MeOH}$, and $4 \mathrm{~mL} \mathrm{MQ}$ water. Samples were then loaded

136 onto cartridges at an approximate flow rate of $1 \mathrm{drop} / \mathrm{sec}$. Cartridges were then allowed to dry under

137 vacuum for $5 \mathrm{~min}$ and eluted with $4 \mathrm{~mL} \mathrm{MeOH}$ and $4 \mathrm{~mL} 0.1 \% \mathrm{NH}_{4} \mathrm{OH}$ in $\mathrm{MeOH}$. Eluent was collected in

$13815 \mathrm{~mL}$ polypropylene tubes containing $200 \mathrm{mg}$ ENVI Carb sorbent. Following vortexing and

139 centrifugation (10 $\mathrm{min} \times 4,000 \mathrm{rpm}$ ), the resulting supernatant was transferred to $50 \mathrm{~mL}$ polypropylene

140 tubes. The ENVI Carb sorbent was rinsed with $\mathrm{MeOH}$, centrifuged, and the resulting supernatant was

141 decanted and combined with the prior sample fraction. Samples were evaporated to dryness, and 
reconstituted using 50:50 water:MeOH with $2 \mathrm{~mL}$ ammonium acetate. Solutions were microcentrifuged

143 at 15,000 rpm for $15 \mathrm{~min}$ and transferred to autosampler vials for analysis.

144 Sample extracts were analyzed for 24 PFAS using an Agilent (Santa Clara, CA, U.S.A.) 6460 triple

145 quadrupole liquid chromatograph tandem mass spectrometer (LC-MS/MS) equipped with an Agilent

1461290 Infinity Flex Cube online SPE, following previously published methods with slight modifications

147 (Weber et al. 2017). A $100 \mu \mathrm{L}$ aliquot of each sample extract was injected and loaded onto an Agilent

148 Zorbax SB-Aq $(4.6 \times 12.5 \mathrm{~mm} ; 5 \mu \mathrm{m})$ online SPE cartridge with $0.85 \mathrm{~mL}$ of $0.1 \%$ formic acid at a flow rate

149 of $1 \mathrm{~mL} \mathrm{~min}{ }^{-1}$. Following sample loading, analytes were eluted from the SPE cartridge and loaded onto

150 an Agilent Poroshell 120 EC-C18 $(3.0 \times 50$ mm; $2.7 \mu \mathrm{m})$ reversed-phase HPLC column using ammonium

151 acetate $(2 \mathrm{mM})$ in $\mathrm{MQ}$ water $(\mathrm{A})$ and ammonium acetate $(2 \mathrm{mM})$ in $\mathrm{MeOH}(\mathrm{B})$ at a flow rate of $0.5 \mathrm{~mL}$

$152 \mathrm{~min}^{-1}$ and a column temperature of $50^{\circ} \mathrm{C}$. Initial gradient conditions were $97 \% \mathrm{~A}$ and $3 \% \mathrm{~B}$. From 0.85 to

$153 \quad 3.5$ min the gradient was linearly increased to $54 \%$ B and from 3.5 to 15 mins, linearly increased to $85 \%$

154 B, before increasing to $100 \%$ B and maintaining at $100 \%$ B from 15.5 to 16.5 mins. Sample analytes were

155 introduced to the tandem mass spectrometer after being ionized with an electrospray ionization source

156 operated in negative ion mode at a temperature of $300^{\circ} \mathrm{C}$, gas flow rate of $13 \mathrm{~L} \mathrm{~min}^{-1}$, and nebulizer

157 pressure of 45 psi.

$158 \quad 2.3$ Quality assurance and quality control

159 Matrix spikes and procedural blanks were included with the sample set to monitor matrix

160 effects, process recovery, and background contamination. Matrix effects were addressed using a 7-point

161 matrix-matched curve, made up of chicken egg homogenate extracted in an identical fashion to egg

162 samples, and spiked with native and isotope-labelled standards directly prior to analysis. The chicken

163 egg matrix used for the curve contained trace levels of n-PFOS and was corrected for background n-

164 PFOS using the average of triplicate chicken egg samples taken through the extraction. Recoveries for

165 detected compounds ranged from 27 - 150\% for FOSA, perfluorotridecanoate (PFTrDA), and 
perfluorotetradecanoate (PFTeDA) having the lowest recoveries due to predictable loss of these

167 analytes during sample preparation (Taniyasu et al. 2005). Excluding these outliers, average analyte recovery ranged from $63-150 \%$, with an average recovery of $78 \%$. Data reported in this study were not blank corrected, due to low levels of process contamination identified in procedural blanks. Method

170 detection limits (MDLs) were defined as procedural blank levels of a given analyte plus 3 times the

171 standard deviation. In the absence of quantifiable blank concentrations, the lowest curve point (0.25

$172 \mathrm{ng} / \mathrm{mL}$ ) was deemed the method detection limit. Values below MDLs were considered zero for

173 summation purposes. Summary statistics and group comparisons were derived using uncensored data

174 analyzed using the cenfit function in the R package NADA version $1.6-1.1$ (Lee 2020) to account for

175 artifacts of left-censored data (Helsel 2011). Significant differences in contaminant concentrations

176 among colonies were assessed using both uncensored and censored log-transformed data. The cendiff

177 function in the R package NADA, which uses Kaplan-Meier (KM) model estimates, was used to evaluate

178 group differences via Peto \& Peto modification of the Gehan-Wilcoxon test. Left-censored data was also 179 assessed for significant differences by habitat and compound using Kruskal-Wallis tests followed by 180 post-hoc application of Dunn's test for multiple comparisons.

\section{$181 \quad 2.4$ GPS Tracking and Spatial Analysis}

Movements of representative adult brown pelicans were ascertained via GPS satellite tracking

183 during the nesting period. GPS-equipped pelicans were not the same individuals from which eggs were

184 collected; therefore comparisons between contaminant exposure and movement are population-based

185 (i.e., at the level of the colony) and not individual-based. For the purposes of contaminant exposure, we 186 also assume that habitat use before and after egg laying is approximately equivalent. Adult pelicans

187 typically spend 2-3 weeks at the colony engaged in courtship activities (e.g. nest site selections, mate 188 advertisement, nest construction) prior to egg laying (Schreiber 1977) and during incubation and chick189 rearing forage within the vicinity of the colony while mates trade-off incubation, nest attendance, and 
provisioning duties. A total of 68 solar-powered GPS-PTT units (GeoTrak Inc., North Carolina, USA) were

191 deployed annually in spring/summer from 2017-2020 on adult pelicans during incubation or early (i.e. 2-

1924 weeks post-hatch) chick-rearing (Castle Pinckney, $n=20$; Bird Key Stono, $n=25$; Deveaux Bank, $n=$

193 23). Transmitters weighed $\sim 65 \mathrm{~g}(10 \times 3.3 \times 3 \mathrm{~cm})$ and were $\leq 3 \%$ body mass of instrumented pelicans

194 (range $=2475-4350$ g). Adult pelicans were captured at the nest with either a leg or neck lasso and

195 equipped in the field. Transmitters were attached dorsally via a backpack-style harness system as

196 described in Lamb et al. (2017a), and were programmed to record 12 GPS positional fixes per day at 90

197 min intervals between the hours of 10:00 - 02:30 GMT (fixes limited by power availability). Unit error

198 was assumed to be approximate to that of Lamb et al. (2017b), i.e. $4.03 \pm 2.79 \mathrm{~m}$. Equipped pelicans

199 were typically released within 20 mins of capture and $50 \mathrm{~m}$ of the nest site.

200 We used a recursive detection algorithm in the $\mathrm{R}$ package recurse (Bracis et al. 2018) to identify

201 nest-site attendance of instrumented pelicans for delimiting breeding locations. Exact nest coordinates

202 were extracted from release locations, with a $250 \mathrm{~m}$ radius buffer established around each nest. Regular

203 nest attendance was defined as the presence of locational fixes within the $250 \mathrm{~m}$ radius buffer

204 separated by $\leq 168 \mathrm{hrs}$. This relatively conservative time cutoff was chosen to balance the infrequency

205 of locational fixes compared to the amount of time an adult may spend at the nest, which decreases as

206 chicks age (Sachs \& Jodice 2009), with the observation that pelican chicks may be able to survive

207 without provisioning for at least $2-3$ wks (Shields 2020). All GPS points were then extracted from initial

208 deployment to the last date of nest attendance for each individual. For pelicans that remained near the

209 nest site beyond the breeding season (i.e. non-migratory individuals), a 90-day cutoff was imposed for

210 adults that were initially instrumented with chicks and a 120-day cutoff for adults initially instrumented

211 with eggs, corresponding to the maximum recorded time to successfully raise offspring (Lamb et al.

212 2017b, Shields 2020). We included telemetry data from both incubation and chick-rearing stages in

213 spatial analyses, as the majority of locations were collected during chick-rearing. It should be noted that 
214 home ranges tend to decrease in size as chicks age, so estimates of overlap in high-use areas by colony 215 may be somewhat biased towards increased segregation (Geary et al. 2019). However, home range size 216 reduction is driven by increased foraging site fidelity, so that habitats used during chick-rearing are 217 derived from those used during incubation (Geary et al. 2019).

218 Breeding movements included $n=22,274$ locational fixes and ranged from 12 May -21 October 219 within each year (mean duration $=34.4 \pm 27.8$ days). To identify high-use areas for each colony, we 220 utilized a grid-cell based approach based on the number of GPS fixes per cell. To reduce spatial bias 221 introduced by time spent at the nest, all points within $250 \mathrm{~m}$ of the relevant breeding colony were 222 removed. A $2.25 \mathrm{~km}^{2}$ grid was then imposed over the study area, and the number of locations in each 223 cell was calculated using ArcMap version 10.1 (ESRI, Redlands, California, USA). For each colony, the 224 upper quartile (25\%) of grid cells containing the most points was defined as the area of high use and 225 subsequently mapped. The upper quartile was chosen in part because the majority of cells above this 226 threshold contained multiple relocations, indicating high use; additional grid cells beyond this level were 227 populated almost exclusively by single relocations which is likely not reflective of frequent use at the 228 population level. We used the boundaries of 8-digit watersheds along the coastline of South Carolina to describe 230 potential differences in urban habitat use by pelicans from each colony. We chose to use watershed 231 boundaries not only because they are ecologically meaningful for coastal birds, but also because each 232 watershed likely has a varying contaminant profile based on differences in source inputs. Hydrologic unit 233 levels are defined by the U.S. Geological Survey and represent the standard units of measurement for 234 describing watersheds. These definitions correspond to regional, subregional, accounting, and 235 cataloging levels (nested from largest to smallest in size, respectively). 8-digit watersheds correspond to 236 the cataloging level, and are therefore of relatively high resolution. Watershed boundaries were 237 obtained from the S.C. Watershed Atlas (SCDHEC 2020a). Within ArcMap, we calculated the relative 
percentages of dominant land cover types by watershed following the Anderson Level I Land Use

239 classification system (Anderson 1976) using data from the 2016 USGS National Land Cover Database (Jin

240 et al. 2019). We also calculated the number of facilities with a National Pollutant Discharge Elimination

241 Discharge (NPDES) permit registered in each watershed (SCDHEC 2020b). Finally, the percentage of high-

242 use grid cells for each pelican colony that occurred in each watershed was calculated as a measure of

243 overlap with urbanized habitats, for the purpose of making qualitative comparisons in urban habitat use

244 between colonies. In this way, we expected that eggs from pelican colonies linked to highly urbanized

245 habitat use (i.e., a large percentage of high-use grid cells occurring in watersheds dominated by urban

246 land cover) would contain greater concentrations of PFAS than eggs from pelican colonies linked to

247 lower urban habitat use if urban exposure was indeed a reliable predictor of PFAS contamination (e.g.,

248 Adams et al. 2008) .

\subsection{RESULTS AND DISCUSSION}

Of the 24 PFAS analytes assessed (Table S1), 15 were measured above detection limits in $\geq 50 \%$

252 of pelican eggs sampled across colonies (Table 1). Perfluorohexanesulfonic acid (PFHxS), PFOS, PFOA, 253 perfluorononanoic acid (PFNA), perfluorodecanoic acid (PFDA), perfluoroundecanoic acid (PFUnDA), 254 perfluorododecanoic acid (PFDoA), and PFTeDA were found in $100 \%$ of tested samples. When averaged 255 by colony location, eggs from Deveaux Bank contained the highest mean SPFAS concentration (202 \pm 256148 ng/g w wt, $n=12)$, followed by Castle Pinckney (192 \pm 137 ng/g w wt, $n=12)$, and Bird Key Stono

$257(132 \pm 46 \mathrm{ng} / \mathrm{g} \mathrm{w} w \mathrm{w}, \mathrm{n}=12)$, although these differences were not statistically significant likely due to the 258 high variability among samples within colonies (Figure 3). The most abundant compound across all 259 samples was $n-P F O S$ (mean $=127.5 \pm 17.5$; range $=48-546 \mathrm{ng} / \mathrm{g} \mathrm{w} w \mathrm{wt}, \mathrm{n}=36$ ). After $\mathrm{n}$-PFOS, the 260 following most abundant compounds included PFDA (12.7 $\pm 0.8 ; 3-25 \mathrm{ng} / \mathrm{g} \mathrm{w} w \mathrm{wt})$, PFUnDA $(7.5 \pm 0.5 ; 2$ $261-14 \mathrm{ng} / \mathrm{g} \mathrm{w} w \mathrm{w})$, PFTrDA $(6.2 \pm 0.5 ; 0-15 \mathrm{ng} / \mathrm{g} \mathrm{w} \mathrm{wt})$, and PFNA $(4.1 \pm 0.2 ; 1-7 \mathrm{ng} / \mathrm{g} w \mathrm{wt})$. Of these, 
only PFNA exhibited significant differences in concentrations among colonies, being higher at Deveaux

263 Bank compared to Castle Pinckney (Figure 4). Other analytes found to significantly differ in

264 concentration among colonies were FOSA, perfluoropentanoic acid (PFPeA), and PFOA although the

265 pattern of differences among colonies differed among analytes (Figure 4). Concentrations of all

266 remaining analytes examined did not differ significantly among colonies. Although few statistical

267 differences were found, we should note some caution may be warranted given the relatively small

268 number of sampled eggs and potential limitations of statistical power.

269 Five watersheds contained at least $10 \%$ of high-use grid cells for any of the three pelican

270 colonies, including the Edisto River, St. Helena Island, Cooper River, Bulls Bay, and Stono River

271 watersheds. Of these, the most highly urbanized watershed was the Cooper River (17.3\% developed

272 land), which also contained nearly 4 times the number of NPDES-registered facilities (68) as the next

273 nearest watershed (Table 2). All remaining watersheds contained $<10 \%$ developed land cover, and $<20$

274 NPDES facilities. Pelicans from Castle Pinckney used the Cooper River watershed the most frequently

275 (58.8\% overlap), while use by individuals from Bird Key Stono was infrequent (8.9\%) and use by

276 individuals from Deveaux Bank was absent(Table 2). Individuals from Bird Key Stono instead used all five

277 watersheds at relatively similar levels (range $=8.9-28.3 \%$ ), while over half of the high-use grid cells for

278 individuals from Deveaux Bank occurred within the Edisto River watershed.

$279 \quad 3.2$ Potential Sub-lethal Effects

280 Brown pelican eggs from the Charleston region displayed relatively elevated levels of $\sum$ PFAS (175.4 \pm

$281120.1 \mathrm{ng} / \mathrm{g} \mathrm{w} \mathrm{wt}$ ) compared to published values of SPFAS from eggs of other seabirds (Table S2). These

282 high concentrations were driven in large part by PFOS loads in individual eggs. Exposure to PFAS may

283 precipitate reproductive impacts for seabirds, including pelicans. Critically, it remains unclear exactly

284 which PFAS analytes or mixtures of analytes may induce reproductive impairment and at what

285 concentrations these effects begin to manifest (Custer 2021). Research examining reproductive impacts 
286 to wild populations in field setting is especially limited (Custer 2021). Tree swallows (Tachycineta

287 bicolor) at a contaminated location experienced a detectable reduction in hatching success when PFOS

288 levels in eggs were as low as $148 \mathrm{ng} / \mathrm{g} \mathrm{w}$ wt, and a $50 \%$ reduction in hatching success compared to the

289 average rate throughout the USA with PFOS levels of $494 \mathrm{ng} / \mathrm{g}$ w wt (Custer et al. 2014). In the current

290 study, 5 of 36 pelican eggs were above the $148 \mathrm{ng} / \mathrm{g}$ value and 2 of 36 were above the $494 \mathrm{ng} / \mathrm{g}$ value.

291 Tartu et al. (2014) reported a correlation between plasma PFDoA concentrations and reduced hatching

292 success in black-legged kittiwakes (Rissa tridactyla) from the Arctic. Additional research on tree

293 swallows as well as great tits (Parus major) has suggested a possible association between reduced

294 hatching success and elevated levels of PFDA at concentrations similar to those found in pelican eggs

295 from this study (Groffen et al. 2019, Custer 2021). Taken together, these results suggest that further

296 study of hatchability in relation to concentrations of PFAS may be warranted at pelican colonies in the

297 region.

$298 \quad 3.3$ FOSA Contamination and Recent Exposure

The concentrations of the semi-volatile precursor compound FOSA measured in brown pelican

300 eggs (mean $=1.0 \pm 0.1$, range $=0-3 \mathrm{ng} / \mathrm{g} \mathrm{w} \mathrm{wt}$ ) suggest relatively recent inputs of PFAS into the

301 Charleston system extending beyond the phase-out period for this compound (Robuck et al. 2020). As

302 avian consumers may have the capacity to biotransform FOSA in vivo to more stable compounds (e.g.

303 PFOS; Gebbink et al. 2009), significant concentrations of precursor compounds may indicate that the

304 metabolic capacity for transformation has been exceeded as a result of continued, elevated exposure to

305 FOSA or other FOSA-precursors (Gebbink et al. 2016, Robuck et al. 2020). For example, over the period

306 1990-2010, Gebbink et al. (2011) were unable to detect FOSA in herring gull (Larus argentatus) eggs

307 from the Great Lakes after 2006 which is consistent with industrial PFAS phase-outs during that same

308 time period. Importantly, FOSA generally declined throughout the two decades of study, with

309 concentrations never exceeding $1.7 \mathrm{ng} / \mathrm{g}$ w wt (Gebbink et al. 2011). A follow-up study also was unable 
310 to detect FOSA and other precursor compounds from eggs of herring gulls in the same area (Letcher et

311 al. 2015). These patterns suggest that the occurrence of FOSA in our samples may be due to continued

312 exposure and not to historic exposure, particularly given that we found brown pelican eggs with

313 maximum concentrations of FOSA approaching $3 \mathrm{ng} / \mathrm{g} w$ wt (Table 1).

314 FOSA was also one of four compounds with significant differences in concentrations among

315 colonies, and was most elevated in eggs from Castle Pinckney. Foraging pelicans from this urban colony

316 consistently showed frequent use of the Cooper and Ashley Rivers during the breeding season compared

317 to pelicans from Bird Key Stono and Deveaux Bank, which both had relatively low overlap of high-use

318 areas with the Cooper River watershed (Table 2). Together with the ability of FOSA to be

319 biotransformed, and therefore the increased likelihood of relatively recent exposure, the spatial

320 segregation of daily breeding-season movements found here suggest that differences in habitat used for

321 foraging during reproduction may at least partially contribute to the loads of this precursor compound.

322 Establishing interannual trends of FOSA concentrations from urban colonies such as Castle Pinckney may

323 therefore assist efforts to determine changes in regional production or use that may drive changes in

324 FOSA or FOSA precursor concentrations in the environment.

\section{$325 \quad 3.4$ Other Differences in Analytes}

While FOSA is likely influenced primarily by recent inputs of FOSA or its precursors into the local

327 environment, observed differences in PFNA, PFPeA, and PFOA concentrations between colonies are

328 likely influenced not only by freshwater industrial sources of these perfluorocarboxylic acids (PFCA).

329 Most likely, the latent transport, oxidation, and accumulation of PFCA precursors will have contributed

330 to the observed PFCA in the marine environments and biota (Ellis et al. 2004, Thackray et al. 2020). For

331 example, Zhang et al. (2019) observed higher than expected bioaccumulation of PFPeA in marine

332 plankton off the northeastern Atlantic coast of the United States, and attributed this to the in situ

333 biotransformation of precursors. Several studies have implied that the consumption of marine prey is 
334 causing a PFAS profile enriched in longer-chain PFCAs, including PFNA (Dassuncao et al. 2017, Robuck et

335 al. 2020). Indeed, longer chain PFCAs have been increasing linearly with time in seabird eggs globally

336 (Gebbink et al. 2011, Miller et al. 2015, Pereira et a. 2021), perhaps as a result of an increased

337 bioaccumulation ability of longer-chain compounds or an increase in their anthropogenic use. Pelican

338 eggs from the current study contained high concentrations of several long-chain PFCAs (e.g. PFDA and

339 PFUnDA) compared to shorter-chain analytes, and this may be a result of their highly marine diet.

\subsection{Similarities in Contamination Profiles Among Colonies}

A thorough assessment of contaminant profiles within an ecosystem is possible only when

342 multiple species and temporal points are considered. For example, Adams et al. (2008) examined PFAS

343 contamination in plasma of bottlenose dolphins from the Charleston region and suggested a positive

344 relationship between contaminant concentrations and urban habitat use immediately following

345 industrial PFAS phaseouts, which was consistent with our initial prediction. While the overall pattern of

346 analyte abundance in the plasma of dolphins was similar to that found in pelican eggs during our study

347 (PFOS > PFDA > PFUnDA > PFNA > PFOA), dolphins residing primarily in or near the harbor exhibited

348 significantly higher concentrations of PFOS, PFDA, and PFUnDA compared to those living in a less

349 urbanized environment (i.e., the Stono River estuary; Adams et al. 2008). No differences were found

350 spatially for PFOA and PFNA (Adams et al. 2008). In contrast, we found no differences in levels of PFOS,

351 PFDA, or PFUnDA among pelican colonies based on the same land cover and watershed classifications,

352 while reporting significant differences for PFOA and PFNA (Fig. 3). Of note is that pelicans from Deveaux

353 Bank, which primarily used the Edisto River watershed, had the highest concentrations of PFOA and

354 PFNA in sampled eggs. Two non-exclusive hypotheses explaining the spatial structuring found in Adams

355 et al. (2008) compared to our results are that (i) the dolphin study reflected the direct release of PFAS

356 from local point sources before industrial phaseouts in comparison to our study that occurred after

357 phaseouts were implemented or that (ii) dolphins in the region may have displayed a higher degree of 
fidelity to specific locations compared to pelicans, especially across the annual cycle (i.e. a lack of

359 migration in dolphins). The contrast between our results and those of Adams et al. (2008) highlights the

360 need to examine multiple apex predators with different life histories and at different temporal points

361 when investigating contaminant profiles for a given region.

362 Indeed, the relatively broad similarities in concentrations of the majority of PFAS analytes

363 among the three pelican colonies in our study suggest that the frequency of using highly urbanized

364 watersheds by foraging adults cannot reliably predict PFAS concentrations in eggs of brown pelicans.

365 Lamb et al. (2020) made a similar conclusion when assessing concentrations of polycyclic aromatic

366 hydrocarbons (PAHs) in blood samples of adult brown pelicans from the northern Gulf of Mexico. There,

367 it was expected that PAHs would differ among regions of the Gulf based on differing background levels

368 of oil and gas activity but the data did not consistently support that supposition. Lamb et al. (2020)

369 posited that other inputs unrelated to the level of oil and gas activity and extensive ranging patterns in

370 individuals may have contributed to the lack of consistent regional differences. Similarly, Newtoff \&

371 Emslie (2017) were unable to find differences in methylmercury concentrations in pelican eggs between

372 two estuarine complexes with differing intensities of anthropogenic influence, contrary to expectations.

373 While some tissues (e.g. blood) reflect relatively local contamination due to their high turnover times,

374 and therefore tend to minimize the influence of migratory and non-breeding areas in determining

375 source locations (Miller et al. 2020 but see Leat et al. 2013), eggs primarily reflect the contamination

376 levels of the nutrient sources that were used to create them (Bond \& Diamond 2010). Individuals may

377 mobilize nutrients for egg production from energy reserves acquired while on migratory or non-

378 breeding areas (capital strategy) or through the rapid conversion of local resources obtained at the

379 breeding grounds (income strategy) (Drent \& Daan 1980). Capital and income strategies are best

380 represented, however, not as dichotomous alternatives but as two endpoints on a spectrum containing

381 many intermediates (Meijer \& Drent 1999). While the balance of endogenous versus exogenous 
nutrients involved in egg deposition in brown pelicans remains unclear, it is likely to be a combination of 383 sources rather than one or the other in totality.

According to traditional life-history theory, species with large body sizes or those undertaking relatively short migrations are likely to favor a capital breeding strategy (Klaassen et al. 2006). Brown pelicans are one of the largest avian species in North America and exhibit a facultative partial migration that can range from completely sedentary to highly migratory (Lamb et al. 2017b). However, brown pelicans also lay relatively small eggs compared to other seabirds and a full clutch may comprise $<8 \%$ body mass of an average adult (Bartholomew \& Goldstein 1984). Pelicans may therefore pay a relatively low energetic cost for producing eggs, suggesting a reduced need to build energetic reserves for this purpose. The local estuarine systems inhabited by pre-breeding pelicans are also likely relatively productive, unlike more temperate or polar systems favored by capital breeders that may not be as predictably productive during pre-breeding for individuals returning from wintering areas (Schelske \&

394 Odum 1962, Hahn et al. 2011, Hupp et al. 2018). Results from Geary et al. (2020) indicated that adult 395 pelicans begin the reproductive cycle foraging in suboptimal habitats relative to the surrounding 396 environment, foraging in optimal habitats only as chicks age and energetic costs rise. This suggests that 397 local productivity is not a limiting factor when considering resource acquisition immediately following 398 egg laying, and that pre-breeding conditions are likely capable of providing the energy necessary for egg 399 formation as well.

400 If brown pelicans are therefore capable of using local resources for egg production, their 401 reliance on foraging habitats at the interface of actively dynamic and complex estuarine systems near 402 Charleston may pose a significant risk for PFAS contamination, as the potential for the release, 403 transport, and accumulation of harmful anthropogenic compounds appears high. Prior investigations 404 into both abiotic and biotic PFAS concentrations centered on the estuarine regions of Charleston suggest 405 that the surrounding aquatic environment, particularly the Cooper River watershed, may indeed be 
more heavily contaminated than other comparable urbanized estuaries (White et al. 2015, Fair \& Houde

407 2018, Fair et al. 2019). Identifying specific source inputs of PFAS in the Charleston region, however, is

408 difficult. Candidate sources include PFOS-contaminated groundwater associated with relatively recent

409 releases of aqueous film-forming foams (AFFF) from Joint Charleston Air Force Base near the Ashley

410 River (U.S. Army Corps of Engineers 2018), as well as older AFFF events from the former Charleston Navy

411 Base on the Cooper River (operational from 1901-1996) (White et al. 2015). Wastewater treatment

412 plants (WWTP) discharging effluent into Charleston Harbor have also been identified as potential

413 sources, with tested effluent containing relatively large amounts of both PFOS and PFOA (Houde et al.

414 2006b). Other suggested point sources include commercial container ships entering the Port of

415 Charleston as well as various anthropogenic activities along freshwater inputs, especially the Cooper

416 River, which aggregates discharge from numerous industrial facilities indicated by NPDES permit

417 registries (White et al. 2015, Leads \& Weinstein 2019) (Figure 1). Importantly, increasing concentrations

418 from 2004-2012 of some compounds in estuarine sediments from the Charleston area suggest

419 continuing inputs into the system despite widespread production bans in the early 2000s (White et al.

420 2015). Although the Cooper River watershed contained the highest levels of urban development as well

421 as the most NPDES facilities, no watersheds examined were completely free of development or

422 discharge facilities, indicating the widespread potential for PFAS exposure throughout the entirety of the

423 study area.

424 However, if egg production is reliant instead on resources acquired during the non-breeding

425 season or while migrating, local point sources of PFAS in urban Charleston may have a reduced impact

426 on observed egg concentrations. Linking overwintering areas with contaminant exposure in brown

427 pelicans is difficult and compounded by the relatively broad range occupied at the population level,

428 driven by variation in post-breeding movements at the level of the individual (Poli 2015). For example,

429 pelicans from colonies in the northern Gulf of Mexico did not exhibit uniform migratory strategies 
among individuals but instead displayed a range of behaviors from complete sedentarism to long-

431 distance migrations (e.g., 1500 km; Lamb et al. 2017b). Preliminary observations of GPS-tracked

432 pelicans from our study colonies in South Carolina, as well as earlier tracking work by Poli (2015),

433 suggest that high-use areas during the non-breeding season occur in coastal Georgia, Florida Bay, and

434 Cuba, as well as along the central and southern coast of South Carolina (i.e., our study area). Each of the

435 aforementioned regions is likely to have a discrete contaminant profile based on anthropogenic activity,

436 local abiotic factors, and regional transport mechanisms (O'Connell et al. 2010, Robuck et al. 2020). The

437 highly variable nature of pelican migratory destinations, both within and between individuals, may

438 therefore have homogenized contaminant exposure between breeding colonies over relatively long

439 temporal scales. This study highlights the need to resolve the relative importance of endogenous versus

440 exogenous resources in eggs when examining contaminants in avian species for making assessments

441 about where contamination may occur during the annual cycle.

442 A limitation of the current study was that we were unable to assess local habitat use for the

443 same individual pelicans from which eggs were collected, due to logistical difficulties, instead relying on

444 colony-level assessments of both movement and contaminant levels. The conclusions made are

445 therefore applicable at the level of the colony, and may not reflect how individual-specific habitat use

446 and movement patterns contributes to PFAS levels. Future studies may better resolve potential

447 associations between habitat use and PFAS contamination by tracking and assaying the same individual.

\section{$448 \quad 4.1$ Conclusion}

449 Our results indicate that potentially impactful ¿PFAS concentrations exist in brown pelican eggs

450 from the Charleston region. Taken together with previous studies as well as known releases of PFAS in

451 the region (i.e. AFFF exposure from military installations), it appears that Charleston may act as a

452 significant source for these contaminants in the nearshore environment. Impacts of this contamination

453 remain unclear but the potential for reproductive or physiological impairment at current exposure levels 
appears to be possible based on previous avifaunal studies (Custer 2021). Contrary to expectations, we

455 were unable to find a relationship between PFAS contamination and use of urbanized habitats for the

456 majority of analytes studied. We therefore suggest that proximity to likely point sources for

457 environmental contaminants may not always act as a reliable proxy for exposure when both stressor

458 and organism are capable of transboundary movement, and that individuals even relatively distant from

459 likely sources may still show elevated risk. Given that brown pelicans were previously listed under the

460 Endangered Species Act largely as a result of interactions with anthropogenic contaminants (Wilkinson

461 et al. 1994), continued monitoring of this species for PFAS contamination may be particularly valuable

462 (Vander Pol et al. 2012).

\section{ACKNOWLEDGEMENTS}

464 We would like to thank St. Johns Yacht Harbor for logistical support. Landis Pujol provided assistance in 465 the field. Stacy Schuur and the National Institute of Standards and Technology (NIST) provided key support advising data collection and housing samples. Felicia Sanders, Janet Thibault, and South Carolina Department of Natural Resources (SCDNR) were instrumental accessing pelican colonies. The South Carolina Cooperative Fish and Wildlife Research Unit is jointly supported by the U.S. Geological Survey, South Carolina DNR, and Clemson University. R.L., A.R.R., and H.M.P. acknowledge support from the NIEHS STEEP Superfund Research Program at URI (Grant P42-ES027706). A.R.R. also acknowledges financial support from the U.S. National Oceanic and Atmospheric Administration (NOAA) Dr. Nancy Foster Scholarship Program (NA17NOS4290028). P.G.R.J. and B.P.W. acknowledge research funding by the U.S. Geological Survey Ecosystems Missions Area, and facilitated by Mona Khalil. Any use of trade, firm, or product names is for descriptive purposes only and does not imply endorsement by the U.S. Government.

\section{REFERENCES}

Adams, J., Houde, M., Muir, D., Speakman, T., Bossart, G., \& Fair, P. (2008). Land use and the spatial distribution of perfluoroalkyl compounds as measured in the plasma of bottlenose dolphins (Tursiops truncatus). Marine environmental research, 66(4), 430-437.

Adams, J., Speakman, T., Zolman, E., Mitchum, G., Wirth, E., Bossart, G. D., \& Fair, P. A. (2014). The relationship between land use and emerging and legacy contaminants in an Apex predator, the bottlenose dolphin (Tursiops truncatus), from two adjacent estuarine watersheds. Environmental Research, 135, 346-353.

Anderson, J. R. (1976). A land use and land cover classification system for use with remote sensor data (Vol. 964). US Government Printing Office. 
Ankley, G. T., Cureton, P., Hoke, R. A., Houde, M., Kumar, A., Kurias, J., ... \& Sample, B. E. (2020). Assessing the Ecological Risks of Per-and Polyfluoroalkyl Substances: Current State-of-the Science and a Proposed Path Forward. Environmental Toxicology and Chemistry.

Armitage, J. M., MacLeod, M., \& Cousins, I. T. (2009). Comparative assessment of the global fate and transport pathways of long-chain perfluorocarboxylic acids (PFCAs) and perfluorocarboxylates (PFCs) emitted from direct sources. Environmental science \& technology, 43(15), 5830-5836.

Bangma, J. T., Bowden, J. A., Brunell, A. M., Christie, I., Finnell, B., Guillette, M. P., ... \& Wilkinson, P. M. (2017). Perfluorinated alkyl acids in plasma of American alligators (Alligator mississippiensis) from Florida and South Carolina. Environmental Toxicology and Chemistry, 36(4), 917-925.

Bartholomew, G. A., \& Goldstein, D. L. (1984). The energetics of development in a very large altricial bird, the brown pelican. In Respiration and metabolism of embryonic vertebrates (pp. 347-357). Springer, Dordrecht.

Bond, A. L., \& Diamond, A. W. (2010). Nutrient allocation for egg production in six Atlantic seabirds. Canadian Journal of Zoology, 88(11), 1095-1102.

Bracis, C., Bildstein, K. L., \& Mueller, T. (2018). Revisitation analysis uncovers spatio-temporal patterns in animal movement data. Ecography, 41(11), 1801-1811.

Cabrera-Cruz, S. A., Smolinsky, J. A., \& Buler, J. J. (2018). Light pollution is greatest within migration passage areas for nocturnally-migrating birds around the world. Scientific reports, 8(1), 3261.

Chu, S., \& Letcher, R. J. (2008). Analysis of fluorotelomer alcohols and perfluorinated sulfonamides in biotic samples by liquid chromatography-atmospheric pressure photoionization mass spectrometry. Journal of Chromatography A, 1215(1-2), 92-99.

Crain, C. M., Halpern, B. S., Beck, M. W., \& Kappel, C. V. (2009). Understanding and managing human threats to the coastal marine environment. Annals of the New York Academy of Sciences, 1162, $39-62$.

Custer, C. M., Custer, T. W., Dummer, P. M., Etterson, M. A., Thogmartin, W. E., Wu, Q., ... \& McKann, P. C. (2014). Exposure and effects of perfluoroalkyl substances in tree swallows nesting in Minnesota and Wisconsin, USA. Archives of environmental contamination and toxicology, 66(1), 120-138.

Custer, C. M. (2021). Linking field and laboratory studies: reproductive effects of perfluorinated substances on avian populations. Integrated Environmental Assessment and Management.

Dassuncao, C., Hu, X. C., Zhang, X., Bossi, R., Dam, M., Mikkelsen, B., \& Sunderland, E. M. (2017). Temporal shifts in poly-and perfluoroalkyl substances (PFASs) in North Atlantic pilot whales indicate large contribution of atmospheric precursors. Environmental science \& technology, 51(8), $4512-4521$.

Drent, R. H., \& Daan, S. (1980). The prudent parent: energetic adjustments in avian breeding. Ardea, $68(1-4), 225-252$.

Ellis, D. A., Martin, J. W., De Silva, A. O., Mabury, S. A., Hurley, M. D., Sulbaek Andersen, M. P., \& Wallington, T. J. (2004). Degradation of fluorotelomer alcohols: a likely atmospheric source of perfluorinated carboxylic acids. Environmental science \& technology, 38(12), 3316-3321. 
Fair, P. A., Romano, T., Schaefer, A. M., Reif, J. S., Bossart, G. D., Houde, M., ... \& Peden-Adams, M. (2013). Associations between perfluoroalkyl compounds and immune and clinical chemistry parameters in highly exposed bottlenose dolphins (Tursiops truncatus). Environmental Toxicology and Chemistry, 32(4), 736-746.

Fair, P. A., \& Houde, M. (2018). Poly-and Perfluoroalkyl Substances in Marine Mammals. In Marine Mammal Ecotoxicology (pp. 117-145). Academic Press.

Fair, P. A., Wolf, B., White, N. D., Arnott, S. A., Kannan, K., Karthikraj, R., \& Vena, J. E. (2019). Perfluoroalkyl substances (PFASs) in edible fish species from Charleston Harbor and tributaries, South Carolina, United States: Exposure and risk assessment. Environmental Research, 171, 266-277.

Fenton, S. E., Ducatman, A., Boobis, A., DeWitt, J. C., Lau, C., Ng, C., ... \& Roberts, S. M. (2020). Perand Polyfluoroalkyl Substance Toxicity and Human Health Review: Current State of Knowledge and Strategies for Informing Future Research. Environmental Toxicology and Chemistry.

Geary, B., Walter, S. T., Leberg, P. L., \& Karubian, J. (2019). Condition-dependent foraging strategies in a coastal seabird: evidence for the rich get richer hypothesis. Behavioral Ecology, 1-8.

Geary, B., Leberg, P. L., Purcell, K. M., Walter, S. T., \& Karubian, J. (2020). Breeding brown pelicans improve foraging performance as energetic needs rise. Scientific Reports, 10(1), 1-9.

Gebbink, W. A., Hebert, C. E., \& Letcher, R. J. (2009). Perfluorinated carboxylates and sulfonates and precursor compounds in herring gull eggs from colonies spanning the Laurentian Great Lakes of North America. Environmental Science \& Technology, 43(19), 7443-7449.

Gebbink, W. A., Letcher, R. J., Hebert, C. E., \& Weseloh, D. C. (2011). Twenty years of temporal change in perfluoroalkyl sulfonate and carboxylate contaminants in herring gull eggs from the Laurentian Great Lakes. Journal of Environmental Monitoring, 13(12), 3365-3372.

Gebbink, W. A., Bignert, A., \& Berger, U. (2016). Perfluoroalkyl acids (PFAAs) and selected precursors in the Baltic Sea Environment: Do precursors play a role in food web accumulation of PFAAs?. Environmental science \& technology, 50(12), 6354-6362.

Gewurtz, S. B., Martin, P. A., Letcher, R. J., Burgess, N. M., Champoux, L., Elliott, J. E., \& Weseloh, D. C. (2016). Spatio-temporal trends and monitoring design of perfluoroalkyl acids in the eggs of gull (Larid) species from across Canada and parts of the United States. Science of The Total Environment, 565, 440-450.

Groffen, T., Lasters, R., Lopez-Antia, A., Prinsen, E., Bervoets, L., \& Eens, M. (2019). Limited reproductive impairment in a passerine bird species exposed along a perfluoroalkyl acid (PFAA) pollution gradient. Science of the Total Environment, 652, 718-728.

Hahn, S., Loonen, M. J., \& Klaassen, M. (2011). The reliance on distant resources for egg formation in high Arctic breeding barnacle geese Branta leucopsis. Journal of Avian Biology, 42(2), 159-168.

Helsel, D. R. (2011). Statistics for censored environmental data using Minitab and $R$ (Vol. 77). John Wiley \& Sons.

Henkel, J. R., Sigel, B. J., \& Taylor, C. M. (2012). Large-scale impacts of the Deepwater Horizon oil spill: can local disturbance affect distant ecosystems through migratory shorebirds?. BioScience, 62(7), 676-685. 
Houde, M., Wells, R. S., Fair, P. A., Bossart, G. D., Hohn, A. A., Rowles, T. K., ... \& Muir, D. C. (2005). Polyfluoroalkyl compounds in free-ranging bottlenose dolphins (Tursiops truncatus) from the Gulf of Mexico and the Atlantic Ocean. Environmental Science \& Technology, 39(17), 6591-6598.

Houde, M., Martin, J. W., Letcher, R. J., Solomon, K. R., \& Muir, D. C. G. (2006a). Biological monitoring of polyfluoroalkyl substances: A review. Environmental Science and Technology, 40(11), 34633473.

Houde, M., Bujas, T. A., Small, J., Wells, R. S., Fair, P. A., Bossart, G. D., ... \& Muir, D. C. (2006b). Biomagnification of perfluoroalkyl compounds in the bottlenose dolphin (Tursiops truncatus) food web. Environmental Science \& Technology, 40(13), 4138-4144.

Houde, M., De Silva, A. O., Muir, D. C., \& Letcher, R. J. (2011). Monitoring of perfluorinated compounds in aquatic biota: an updated review: PFCs in aquatic biota. Environmental Science \& technology, 45(19), 7962-7973.

Hupp, J. W., Ward, D. H., Soto, D. X., \& Hobson, K. A. (2018). Spring temperature, migration chronology, and nutrient allocation to eggs in three species of arctic-nesting geese: Implications for resilience to climate warming. Global Change Biology, 24(11), 5056-5071.

Jin, S., Homer, C., Yang, L., Danielson, P., Dewitz, J., Li, C., ... \& Howard, D. (2019). Overall methodology design for the United States national land cover database 2016 products. Remote Sensing, 11(24), 2971.

Jodice, P. G., Murphy, T. M., Sanders, F. J., \& Ferguson, L. M. (2007). Longterm trends in nest counts of colonial seabirds in South Carolina, USA. Waterbirds, 30(1), 40-51.

Jodice, P. G., \& Suryan, R. M. (2010). The transboundary nature of seabird ecology. In Landscape-scale conservation planning (pp. 139-165). Springer, Dordrecht.

Keller, J. M., Alava, J. J., Aleksa, K., Young, B., \& Kucklick, J. R. (2005). Spatial trends of polybrominated diphenyl ethers (PBDEs) in loggerhead sea turtle eggs and plasma. Organohalogen Compounds, $67,610-611$.

Klaassen, M. R. J., Abraham, K. F., Jefferies, R. L., \& Vrtiska, M. (2006). Factors affecting the site of investment, and the reliance on savings for Arctic breeders: the capital-income dichotomy revisited. Ardea, 94(3), 371-384.

Lamb, J. S., Satgé, Y. G., Fiorello, C. V., \& Jodice, P. G. (2017a). Behavioral and reproductive effects of bird-borne data logger attachment on Brown Pelicans (Pelecanus occidentalis) on three temporal scales. Journal of Ornithology, 158(2), 617-627.

Lamb, J. S., Satgé, Y. G., \& Jodice, P. G. (2017b). Influence of density-dependent competition on foraging and migratory behavior of a subtropical colonial seabird. Ecology and evolution, $7(16)$, 6469-6481.

Lamb, J. S., Satgé, Y. G., Streker, R. A., \& Jodice, P. G. R. (2020). Ecological drivers of brown pelican movement patterns, health, and reproductive success in the Gulf of Mexico. New Orleans (LA): US Department of the Interior, Bureau of Ocean Energy Management. 234 p. Report No.: BOEM 2020-036. Contract No.: M12PG00014.

Leads, R. R., \& Weinstein, J. E. (2019). Occurrence of tire wear particles and other microplastics within the tributaries of the Charleston Harbor Estuary, South Carolina, USA. Marine Pollution Bulletin, 145, 569-582. 
Lee, L. (2020). NADA: Nondetects and Data Analysis for Environmental Data. R package version 1.6-1.1. https://CRAN.R-project.org/package=NADA

Letcher, R. J., Su, G., Moore, J. N., Williams, L. L., Martin, P. A., de Solla, S. R., \& Bowerman, W. W. (2015). Perfluorinated sulfonate and carboxylate compounds and precursors in herring gull eggs from across the Laurentian Great Lakes of North America: temporal and recent spatial comparisons and exposure implications. Science of the Total Environment, 538, 468-477.

Lohmann, R., Breivik, K., Dachs, J., \& Muir, D. (2007). Global fate of POPs: current and future research directions. Environmental pollution, 150(1), 150-165.

Meijer, T., \& Drent, R. (1999). Re-examination of the capital and income dichotomy in breeding birds. Ibis, 141(3), 399-414.

Mello, F. V., Roscales, J. L., Guida, Y. S., Menezes, J. F., Vicente, A., Costa, E. S., ... \& Torres, J. P. M. (2016). Relationship between legacy and emerging organic pollutants in Antarctic seabirds and their foraging ecology as shown by $\delta 13 \mathrm{C}$ and $\delta 15 \mathrm{~N}$. Science of the Total Environment, 573, 1380-1389.

Miller, A., Elliott, J. E., Elliott, K. H., Lee, S., \& Cyr, F. (2015). Temporal trends of perfluoroalkyl substances (PFAS) in eggs of coastal and offshore birds: increasing PFAS levels associated with offshore bird species breeding on the Pacific coast of Canada and wintering near Asia. Environmental toxicology and chemistry, 34(8), 1799-1808.

Miller, A., Elliott, J. E., Wilson, L. K., Elliott, K. H., Drouillard, K. G., Verreault, J., ... \& Idrissi, A. (2020). Influence of overwinter distribution on exposure to persistent organic pollutants (POPs) in seabirds, ancient murrelets (Synthliboramphus antiquus), breeding on the Pacific coast of Canada. Environmental Pollution, 259, 113842.

Newtoff, K. N., \& Emslie, S. D. (2017). Mercury exposure and diet in brown pelicans (Pelecanus occidentalis) in North Carolina, USA. Waterbirds, 40(1), 50-57.

O'Connell, S. G., Arendt, M., Segars, A., Kimmel, T., Braun-Mcneill, J., Avens, L., ... Keller, J. M. (2010). Temporal and spatial trends of perfluorinated compounds in juvenile loggerhead sea turtles (Caretta caretta) along the east coast of the United States. Environmental Science and Technology, 44(13), 5202-5209.

Odsjö, T. (1975). Toxic chemicals in sedentary and migratory birds in Fennoscandia and the Baltic Area. Ornis Fennica, 52, 74-82.

Parolini, M., Cappelli, F., De Felice, B., Possenti, C. D., Rubolini, D., Valsecchi, S., \& Polesello, S. (2021). Within-and Among-Clutch Variation of Yolk Perfluoroalkyl Acids in a Seabird from the Northern Adriatic Sea. Environmental Toxicology and Chemistry, 40(3), 744-753.

Pereira, M. G., Lacorte, S., Walker, L. A., \& Shore, R. F. (2021). Contrasting long term temporal trends in perfluoroalkyl substances (PFAS) in eggs of the northern gannet (Morus bassanus) from two UK colonies. Science of the Total Environment, 754, 141900.

Poli, C. (2015). Variability in movement patterns and habitat use of two species of Pelecaniformes. Thesis. Clemson, SC: Clemson University.

Power, A., White, P., McHugh, B., Berrow, S., Schlingermann, M., Tannian, M., ... \& O'Hea, L. (2020). Persistent pollutants in Northern Gannet Morus bassanus eggs in Ireland: Levels and colony differences. Environmental Pollution, 268, 115723. 
Robuck, A., Cantwell, M. G., McCord, J. P., Addison, L. M., Pfohl, M., Strynar, M. J., ... \& Lohmann, R. (2020). Legacy and Novel Per-and Polyfluoroalkyl Substances (PFAS) in Juvenile Seabirds from the US Atlantic Coast. Environmental Science \& Technology, 54(20), 12938-12948.

Rush, S. A., Cooper, R. J., \& Woodrey, M. S. (2007). A nondestructive method for estimating the age of Clapper Rail eggs. Journal of Field Ornithology, 78(4), 407-410.

Sachs, E. B., \& Jodice, P. G. (2009). Behavior of parent and nestling Brown Pelicans during early brood rearing. Waterbirds, 32(2), 276-281.

Schelske, C. L., \& Odum, E. P. (1962). Mechanisms maintaining high productivity in Georgia estuaries.

Schreiber, R. W. (1977). Maintenance behavior and communication in the Brown Pelican. Ornithological Monographs, (22), iii-78.

Shields, M. (2020). Brown Pelican (Pelecanus occidentalis), version 1.0. In Birds of the World (A. F. Poole, Editor). Cornell Lab of Ornithology, Ithaca, NY, USA.

South Carolina Department of Health and Environmental Control (2020, November 19). S.C. Watershed Atlas. https://gis.dhec.sc.gov/watersheds/

South Carolina Department of Health and Environmental Control (2020, November 19). Interactive Maps and Geospatial Data. https://sc-department-of-health-and-environmental-control-gis-scdhec.hub.arcgis.com/

Sunderland, E. M., Hu, X. C., Dassuncao, C., Tokranov, A. K., Wagner, C. C., \& Allen, J. G. (2019). A review of the pathways of human exposure to poly-and perfluoroalkyl substances (PFASs) and present understanding of health effects. Journal of Exposure Science \& Environmental Epidemiology, 29(2), 131-147.

Taniyasu, S., Kannan, K., So, M. K., Gulkowska, A., Sinclair, E., Okazawa, T., \& Yamashita, N. (2005). Analysis of fluorotelomer alcohols, fluorotelomer acids, and short-and long-chain perfluorinated acids in water and biota. Journal of Chromatography A, 1093(1-2), 89-97.

Thackray, C. P., Selin, N. E., \& Young, C. J. (2020). A global atmospheric chemistry model for the fate and transport of PFCAs and their precursors. Environmental Science: Processes \& Impacts, 22(2), 285-293.

U.S. Army Corps of Engineers. (2018). Final Site Inspections Report of Fire Fighting Foam Usage at Joint Base Charleston-Air, Charleston County, and North Auxiliary Airfield, Orangeburg County, South Carolina. U.S. Army Corps of Engineers, Savannah District, Savannah, Georgia.

Vander Pol, S. S., Anderson, D. W., Jodice, P. G. R., \& Stuckey, J. E. (2012). East versus West: Organic contaminant differences in brown pelican (Pelecanus occidentalis) eggs from South Carolina, USA and the Gulf of California, Mexico. Science of the Total Environment, 438, 527-532.

Vicente, J., Sanpera, C., García-Tarrasón, M., Pérez, A., \& Lacorte, S. (2015). Perfluoroalkyl and polyfluoroalkyl substances in entire clutches of Audouin's gulls from the Ebro delta. Chemosphere, 119, S62-S68.

Weber, A. K., Barber, L. B., LeBlanc, D. R., Sunderland, E. M., \& Vecitis, C. D. (2017). Geochemical and hydrologic factors controlling subsurface transport of poly-and perfluoroalkyl substances, Cape Cod, Massachusetts. Environmental Science \& Technology, 51(8), 4269-4279. 
White, N. D., Balthis, L., Kannan, K., De Silva, A. O., Wu, Q., French, K. M., ... \& Fair, P. A. (2015). Elevated levels of perfluoroalkyl substances in estuarine sediments of Charleston, SC. Science of the Total Environment, 521, 79-89.

Wilkinson, P. M., Nesbitt, S. A., \& Parnell, J. F. (1994). Recent history and status of the eastern brown pelican. Wildlife Society Bulletin, 22(3), 420-430.

Zhang, X., Lohmann, R., \& Sunderland, E. M. (2019). Poly-and perfluoroalkyl substances in seawater and plankton from the Northwestern Atlantic Margin. Environmental science \& technology, 53(21), 12348-12356. 